\title{
Waste on the roadside, 'poi-sute' waste: Its distribution and elution potential of pollutants into environment
}

\author{
Hiroshi Moriwaki* $^{1}$, Shiori Kitajima ${ }^{1}$, Kenshi Katahira ${ }^{2}$ \\ ${ }^{1}$ Shinshu University, Faculty of Textile Science and Technology, Department of applied biology, \\ 3-15-1, Tokida, Ueda 386-8567, Japan, E-mail: moriwaki@shinshu-u.ac.jp \\ ${ }^{2}$ Osaka City Institute of Public Health \& Environmental Sciences, 8-34 Tojo-cho, Tennoji-ku, Osaka \\ 543-0026, Japan.
}

* To whom correspondence should be addressed.

E-mail: moriwaki@shinshu-u.ac.jp

\begin{abstract}
Waste on the roadside, 'poi-sute' waste, was collected in a typical suburb in Japan (Ueda city, the sampling course: $3.2 \mathrm{~km}$ ). The distribution, characterization of the "poi-sute" waste and the loading of pollutants from the waste were studied. The average number of total waste was 690 pieces a month, and 220 pieces of waste were dumped a month per $\mathbf{k m}$. There was a tendency for much waste to be discarded around shops staying open until late at night. Regarding the sorts of the waste, cigarette butts are the most (the average was 150 cigarette butts / km/ month), and second was plastic materials. As for the weight, cigarette butts, plastics and papers were at a similar level (about $90 \mathrm{~g} / \mathrm{km} / \mathrm{month}$ ).

The elution of arsenic $(0.041 \mathrm{mg} / \mathrm{L})$ and nicotine $(3.8 \mathrm{mg} / \mathrm{L})$ was ascertained by a dissolution test of 'poi-sute' cigarette butts obtained by sampling. Furthermore, the loading of heavy metals, such as lead, copper, chromium and cadmium, and polycyclic aromatic hydrocarbons (PAHs) from cigarette butts into the environment was confirmed. The load potentials of heavy metals were $0.020-1.7(\mathrm{mg} / \mathrm{km} / \mathrm{month})$, and that of total- polyaromatic hydrocarbons was $0.032(\mathrm{mg} / \mathrm{km} / \mathrm{month})$. These results indicate that the 'poi-sute' waste has a harmful influence on the environment.
\end{abstract}

Key words: dumping of wastes, 'poi-sute' waste, pollution, arsenic, nicotine, polycyclic aromatic hydrocarbons

Running title: Environment pollution by waste on the roadside

\section{Introduction}

There have been many examples of pollutants loaded into the environment by the dumping of wastes. ${ }^{1}$ It is very important to understand the distributions of the dumping of wastes and the quantification of pollutants loaded into the environment by them in order to develop strategies for 
the dumping of wastes. ${ }^{2}$ In this study, we focused on waste dumped on roadside, which is called 'poi-sute' waste in Japanese. 'Poi' refers to the aspect of throwing, and 'sute' means 'discard' in Japanese. In view of the maintenance of the landscape and the environment, the reduction of 'poi-sute' waste has politically important significances, and a grasp of the situations and information on the 'poi-sute' waste is needed.

In many cities of developing countries, waste management is poor, and solid wastes are dumped along roadsides, and there are several reports concerned with the roadside dumping in developing contries. ${ }^{3,4}$ However, there is no report about the quantity, distribution and influence of 'poi-sute' waste on the environment, such as the elution behavior of pollutants from the 'poi-sute' waste, in cities of developed countries, to our knowledge.

We, then, obtained samples of 'poi-sute' waste for 4 months in a typical suburban city in Japan and investigated the distribution, quantity and sorts of the 'poi-sute' waste. In addition, the quantities of pollutants loaded into the environment from 'poi-sute' waste were also studied. The objective of this research is to understand the actual circumstances of the environmental pollution induced by 'poi-sute' waste. This research would present not only a typical example of the relationship between 'poi-sute' waste and environmental pollution but a procedure for studying the 'poi-sute' waste.

\section{Experimental \\ Methodology}

This study was carried out in three stages as follows:

1: Fractionation, mapping and sampling of 'poi-sute' waste.

2: Elution test of cigarette butts with distilled water and $1 \mathrm{~N} \mathrm{HCl}$ aqueous solution.

3: Analysis of heavy metals and polyaromatic hydrocarbons (PAHs) in the test solutions.

\section{Sampling of 'poi-sute' waste}

Samples of 'poi-sute' waste were obtained from the roadside in Ueda city. This city is a typical meso-scale suburb in Japan, which is about 90 minutes by train from Tokyo, and the population has been 160,000. The sampling course was set at the center of Ueda city. As shown in Figure 1a, the area around the course has been used as various applications, such as shops, houses, factories and schools. All waste on the roadside at the sampling course $(3.2 \mathrm{~km})$ was picked up and counted. The location and sorts of the waste are plotted on the map (Figure 1b). The 'poi-sute' waste was sampled five times each month. At first, the 'poi-sute' waste was sampled on May $15^{\text {th }}$ in 2007 by cleaning up all the waste, and the total weight of the waste was $1640 \mathrm{~g}$. We subsequently sampled the waste on June $16^{\text {th }}$, July $16^{\text {th }}$, August $16^{\text {th }}$ and September $14^{\text {th }}$.

Waste composition analysis has been carried out in order to manage the solid waste treatment appropriately. US Environmental Protect Agency characterized municipal solid wastes by grouping wastes under materials; food scraps, paper, glass, metal, plastics, rubber, leather and textiles, wood, yard trimmings and other. ${ }^{5}$ In Japan, wastes was categorized by government test guideline into food scraps, paper, glass, metal, plastics, textiles, wood and other. ${ }^{6}$ By pre-examination of 'poi-sute' waste at sampling site, it is thought that number of food scraps, wood, and cloth are small, and there are large numbers of cigarette butts, bin, can and plastic bottle in the 'poi-sute' waste . Therefore, 'poi-sute' waste was categorized into cigarette butts, plastic materials (plastic bottle, containers and packaging, and other plastic goods), papers, cans and other wastes in this study. Sorts of waste and products are summarized in Table 1. Naturally-occurring waste was not sampled. The obtained waste was brought to the laboratory and weighed. Parts of the cigarette butts were used for the analysis of pollutants.

\section{Materials}

All solvents were of HPLC grade and other chemicals were of analytical-reagent grade. Toluene, ethanol, acetonitrile and nicotine were purchased from Wako Pure Chemical Industries, Ltd. (Osaka, Japan). An ICP-AES standard solution was obtained from SCP Science (Clark Graham, Quebec, Canada). A PAH standard mixture was purchased from SUPELCO (Bellefonte, PA, USA). $\left[{ }^{13} \mathrm{C}_{3}\right]$ Atrazine was purchased from Hayashi Pure Chemicals (Osaka, Japan). Ultra pure water was produced by an automatic water distillation apparatus (NANOpure II, Barnstend, Boston, MA, USA).

Elution test of cigarette butts

An elution test of the cigarette butts, which were highest content in the 'poi-sute' waste and would 
contain various pollutants, was carried out. Five grams of cigarette butts were added to $50 \mathrm{~mL}$ of solution, $1.0 \mathrm{~N} \mathrm{HCl}$ or distilled water, and the suspension was shaken for 2 hours at room temperature. The suspension was centrifuged at $3000 \mathrm{rpm}$ for 10 minutes and filtered through a membrane filter (pore size $0.45 \mu \mathrm{m}$; Millipore, Bedford, MA, USA).

\section{Analytical procedure}

To $20 \mathrm{~mL}$ of the obtained solution was added $10 \mathrm{~mL}$ of nitric acid and the solution heated on a hot plate. After digestion, the solution was diluted to $20 \mathrm{~mL}$ and analyzed for heavy metals, such as As, $\mathrm{Pb}$ and Cd using ICP atomic emission microscopy (SII technology, SPS3100). ${ }^{7}$

Nicotine in the solution obtained by the elution test of cigarette butts was measured by LC/MS. ${ }^{8}$ The LC/MS was performed using an LCMS 2010A (Shimadzu, Kyoto, Japan). Liquid chromatography was carried out on an HPLC apparatus equipped with a Shimadzu HPLC 10ADvp (Shimadzu, Kyoto, Japan). A TOSOH TSK-GEL ODS-100Z (Tosoh, Tokyo, Japan: $3 \mu \mathrm{m}$ particle size, $2.0 \times 150 \mathrm{~mm}$ I.D.) was used for the LC separation. The HPLC separation was carried out at 40 ${ }^{\circ} \mathrm{C}$ using a gradient composed of solution A (ammonium acetate $(1 \mathrm{mM})$ /acetic acid $(2 \mathrm{~mL} / \mathrm{L})$ solution) and solvent $\mathrm{B}$ (methanol). The gradient expressed as changes in solvent $\mathrm{B}$ was as follows: 0-4 min, hold at $1 \% \mathrm{~B}$; 4-8 min, a linear increase from $1 \%$ to $5 \% \mathrm{~B}$; 8-13 min, hold at 5\% B. The flow rate was $0.2 \mathrm{~mL} / \mathrm{min}$. Ionization of the analyte was achieved by electrospray in the positive ion mode. The LC/MS acquisition was performed in the selected-ion monitoring mode (SIM). The 163 ion and 220 ion $(\mathrm{m} / \mathrm{z})$, which were assigned to the $[\mathrm{M}+\mathrm{H}]^{+}$of nicotine and the internal standard, were measured.

An analysis of the PAHs was performed according to the procedure previously reported. ${ }^{9}$ It is briefly summarized as follows. The $0.5 \mathrm{~g}$ cigarette butts samples were extracted by ultrasonic agitation. A $30 \mathrm{~min}$ extraction was carried out in a centrifuge tube with ethanol (4ml) and toluene $(16 \mathrm{ml})$; then the tube was centrifuged at $1500 \mathrm{rpm}$ for $10 \mathrm{~min}$. This treatment was repeated twice. The supernatants were combined and concentrated to $1 \mathrm{ml}$ by a rotary evaporator and then dried in a flowing $\mathrm{N}_{2}$ stream. The residue was dissolved in n-hexane $(2 \mathrm{ml})$. The hexane solution was loaded onto a Sep-Pak Plus silica cartridge (Nihon Waters, Tokyo, Japan). The cartridge was eluted with $10 \mathrm{ml}$ of $\mathrm{n}$-hexane/ toluene $(90: 10, \mathrm{v} / \mathrm{v})$ into a glass tube. The eluent was dried by a nitrogen purge and dissolved in $0.5 \mathrm{ml}$ of acetonitrile. A $1 \mu \mathrm{l}$ acetonitrile solution was injected into the HPLC. The quantification of the PAHs was performed using an HPLC/ fluorescence detector. Chromatograms were obtained from an HPLC 10ADvp interfaced with a fluorescence detector RF-10A $\mathrm{XL}_{\mathrm{XL}}$ (Shimadzu, Kyoto, Japan). The HPLC system was equipped with a Supelcosil LC-PAH (Supelco) reverse-phase C18 column $(2.0 \times 250 \mathrm{~mm}, 5 \mu \mathrm{m}$ particle size $)$. Sample aliquots and the calibration standard $(1 \mu \mathrm{l})$ were injected using an auto sampler. The flow rate was $0.2 \mathrm{ml} / \mathrm{min}$. As the mobile phase, a water/acetonitrile gradient was employed as follows: $0-5 \mathrm{~min}$ acetonitrile $60 \%$; in $30 \mathrm{~min}$ to $100 \%$ acetonitrile and held for $5 \mathrm{~min}$. With the fluorescence detector, excitation was set at 270, 250, 290 and $300 \mathrm{~nm}$ and emissions at 320, 380, 390, 400 and 500nm. The detection limit of the PAHs by this method, defined as three times the standard deviation, varied from $0.003 \mathrm{mg} / \mathrm{kg}$ for benzo(a)pyrene to $0.02 \mathrm{mg} / \mathrm{kg}$ for chrysene.

The roadside soil was sampled at the place $C$ in Figure 1a. The soil sample was dried at room temperature for a week, removed stones and wastes, and sieved (screen size: $5 \times 5 \mathrm{~mm}$ ). The PAH contents in $0.5 \mathrm{~g}$ obtained sample was measured by the same procedure as the PAH analysis of cigarette butts.

\section{Results and Discussion \\ Distribution of 'poi-sute' waste}

The average number of total waste was 690 pieces a month. That is to say, 220 pieces of waste were dumped a month per km. At every four samplings, much waste was obtained in three areas, A, B and $\mathrm{C}$, which are shown in Figure 1a. Place A is around the signal in front of a hypermarket, place B is around the parking area of a round-the-clock coffee house, and place $\mathrm{C}$ is around the parking area of a round-the-clock supermarket. The numbers of waste at these places accounted for 9.7 $\pm 5.2,19 \pm$ 2.4 and $13 \pm 1.8 \%$ of the total for A, B and C, respectively. This fact indicates that there is a tendency for much 'poi-sute' waste to be found at business districts around shops, which are open till late at night. 
A north-south road in the sampling course, Route 18, is an arterial road in this area. Though Route 18 has more traffic than the other roads in the sampling course, there was a tendency for the numbers of 'poi-sute' waste at Route 18 to be less than at the other roads. This result shows that the quantity of 'poi-sute' waste was not simply due to the traffic density but was changed by the land utilization around the roads and the administration and traffic conditions of the roads.

\section{Sorts of 'poi-sute' waste}

The average and standard deviation of the weights and numbers of each kind of waste is summarized in Table 2. In addition, the change in the numbers and weights of waste between months is shown in Figure 2a and $\mathbf{2 b}$, respectively. Most of the waste was cigarette butts, and the average number of cigarette butts per month was 490 (150 cigarette butts / km/ month). The second highest component was plastics. The number of containers and packaging made up most of the sorts of the plastic waste. The average weight of waste at the roadsides per month was $1200 \mathrm{~g}(380 \mathrm{~g} / \mathrm{km} / \mathrm{month})$. The weights of papers, plastics and cigarette butts were at a similar level and were $22-24 \%$ of the total. In addition, the localization of each sorts of waste could not be observed (Figure 1b). Furthermore, significant difference in the percentages of the number and weight of each sorts of waste could not be shown (Figure 2a, 2b).

It was reported that the domestic solid wastes have been often dumped along roadsides in cities of developing countries. ${ }^{4}$ Therefore, the composition of the domestic waste would be similar to that of roadside waste at these sites. In this study, the composition of the domestic waste sampled at the waste treatment center in Ueda City (Food scraps; $25 \%$, Wood; $24 \%)^{10}$ was different from that of 'poi-sute' waste. This result indicates that 'poi-sute' waste in this study is not household waste, but waste made by drivers or walkers at the sampling site.

\section{Elution and loading dose of pollutants in 'poi-sute' cigarette butts}

It is thought that 'poi-sute' waste contains various environmental pollutants. Cigarette butts, in particular, include toxic compounds, such as heavy metals, nicotine and polycyclic aromatic hydrocarbons (PAHs). ${ }^{11,12}$ Heavy metals and nicotine contained in the solution obtained by an elution test of cigarette butts were then measured in order to determine the quantity of these compounds that diffused into the environment. Furthermore, the contents of heavy metals in cigarette butts (quantities of heavy metals extracted by $1 \mathrm{~N} \mathrm{HCl}$ solution) and those of PAHs (quantities of PAHs extracted by toluene/ethanol 9/1 solution) were also analyzed. The results are summarized in Tables 3 and 4.

Regarding the elution test of cigarette butts, arsenic was detected at $0.041 \mathrm{mg} / \mathrm{L}$, though cadmium, copper, lead and chromium were not detected (detection limits: 0.002, 0.002, 0.007 and $0.004 \mathrm{mg} / \mathrm{L}$ ). The level of arsenic was higher than the water quality criterion in Japan $(0.01 \mathrm{mg} / \mathrm{L})$. Arsenic would diffuse from 'poi-sute' cigarette butts into the environment, and that could have an adverse effect on the environment.

The contents of heavy metals in cigarette butts was more than the detection limits for all elements, cadmium, copper, lead, chromium and arsenic, which we measured. The loading doses of these compounds by 'poi-sute' cigarette butts into the environment were 0.02, 1.7, 0.59, 0.15 and 0.81 $\mathrm{mg} / \mathrm{km} / \mathrm{month}$ for cadmium, copper, lead, chromium and arsenic, respectively.

The concentration of nicotine in the eluent of 'poi-sute' cigarette butts was $3.8 \mathrm{mg} / \mathrm{L}$. It is well known that nicotine causes deleterious effects on living organisms. ${ }^{13}$ The results in this study indicate that nicotine in 'poi-sute' cigarette butts can diffuse into the environment through elution of the compounds from 'poi-sute' waste in rainwater. However, it is difficult to evaluate the influence of nicotine in 'poi-sute' cigarette butts on environmental life, because the quantity of eluted nicotine in rainwater and the exposure of rain containing nicotine from the waste to organisms is not clear.

Next, the content of PAHs in cigarette butts was measured. The contents of each PAH were from 0.0065 to $0.091 \mathrm{mg} / \mathrm{kg}$. On the other hand, the concentrations of PAHs in roadside soil samples from the sampling course (place C) were from 0.0058 to $0.36 \mathrm{mg} / \mathrm{kg}$. The detection pattern of the concentrations of PAHs in the roadside soil was similar to that in 'poi-sute' cigarette butts (Table 5). In addition, the detection pattern of the concentrations of PAHs in the roadside soil was different from that of vehicle soot from gasoline engines. ${ }^{14}$ It is thought that the contribution of PAHs from 'poi-sute' cigarette butts to that in roadside soil is not small, although there are many sources of PAHs in roadside soil other than gasoline engines and cigarette butts. 
It is well known that some of the PAHs, such as benzo(a)pyrene (B(a)P), have a high carcinogenicity. ${ }^{15}$ There is a possibility that 'poi-sute' cigarette butts diffuse into the environment and cause adverse effects on living organisms. The average of loading dose of total PAHs by 'poi-sute' cigarette butts was $0.032 \mathrm{mg} / \mathrm{km} / \mathrm{month}$.

\section{Conclusions}

In this paper, the distribution and quantity of 'poi-sute' waste at a typical suburb in Japan was shown. A tendency for much waste to be discarded around shops staying open until late at night was shown. Action against the 'poi-sute' waste, such as the placing waste bins and the appeal the loss in quantity of 'poi-sute' waste to citizen, can be considered as a result of this study. For the relationship between 'poi-sute' waste and environmental pollution, it has become apparent that heavy metals, nicotine and PAHs were loaded into the environment by 'poi-sute' cigarette butts. These results indicate that the regulation of 'poi-sute' cigarette butts should be considered for the preservation of the environment. This study shows that there is a possibility that arsenic was diffused into the environment through rainwater at a higher level compared to water quality criterion in Japan, and the arsenic in cigarette butts has a bad influence on the environment. It is thought that nicotine, which was loaded into the environment from 'poi-sute' cigarette butts, could have a bad influence on livings creatures. However, it is difficult to assess the risk induced by 'poi-sute' waste on living organisms, because the pathways of the waste to the environment, that is to say, diffusion by rain or wind, were too complex. The next step of this study is to evaluate the risk of 'poi-sute' waste including research on the diffusion pathway of the pollutants in 'poi-sute' waste. The sampling interval is very important factor for understanding the diffusion pathway and behavior of 'poi-sute' wastes. In this study, the sampling interval was set for a month. However, further studies of 'poi-sute' waste sampled at different sampling intervals, such as a day, week and year, are needed to grasp the detailed behavior of 'poi-sute' waste.

In addition, next step of this research is to study 'poi-sute' wastes at various sampling sites, such as highway and metropolis, for exploring the influence of the 'poi-sute' wastes on the environment and the cost of 'poi-sute' waste treatment.

\section{Acknowledgement}

This work was supported by Shinshu University Satellite Venture Business Laboratory. The authors thank Dr. Mamoru Sakai (Osaka City Institute for Public Health \& Environmental Sciences) for his advices on the waste composition analysis.

\section{References}

[1] K. Katahira, M. Ishitake, H. Moriwaki, S. Yoshikawa, O. Yamamoto, T. Fujita and H. Yamazaki, Water, Air, \& Soil Pollution, 2007, 179, 197-206.

[2] O. Buenrostro, G. Bocco, G. Bernache, Waste Manag. Res., 2001, 19, 169-176.

[3] R. K. Henry, Z. Yongsheng, D. Jun, Waste Manag., 2006, 26, 92-100.

[4] T. Tadesse, A. Ruijs, F. Hagos, Waste Manag., in press.

[5] U. S. Environmental Protection Agency. Municipal solid waste generation, recycling, and disposal in the United States: Fact and figures for 2006. EPA/530-F-07-030, November 2007.

[6] Japan Ministry of Health, Labor and welfare, Notification 95, November 1977.

[7] Japan Ministry of Environment, Notification 19, March 2003.

[8] T. Chetiyanukornkul, A. Toriba, R. Kizu, K. Kimura, K. Hayakawa, Biomed Chromatogr. 2004, 18(9), 655-61.

[9] H. Moriwaki, K. Katahira, O. Yamamoto, J. Fukuyama, T. Kamiura, H. Yamazaki, S. Yoshikawa, Atmospheric Environment, 2005, 39/6, 1019-1025.

[10] Japan Ministry of Einvironment, 2007. Data of domestic waste in H17. $<$ http://www.env.go.jp/recycle/waste_tech/ippan/h17/data/seibi/city/20.xls > (accessed July 6, 2008).

[11] T. Micerska, M. S. Warne, F. Pablo, R. Patra, Arch. Environ. Contam. Toxicol., 2006, 50, 205-212.

[12] Y. S. Ding, D. L. Ashley, C. H. Watson, J. Agri. Food Chem., 2007, 55, 5966-5973.

[13] S. M. Attia, Mutation Res., 2007, 632, 29-36.

[14] R. Boonyatumanond, M. Murakami, G. Wattayakorn, A. Togo, H. Takada, Sci. Total Environ., 2007, 384, 420-432.

[15] C. E. Boström, P. Gerde, A. Hanberg, B. Jernström, C. Johansson, T. Kyrklund, A. Rannug, M. 
Törnqvist, K. Victorin, R. Westerholm, Environ. Health Perspect., 2002, 110, 451-488.

Figure captions

Fig.1 The map of sampling course (a) and distribution of 'poi-sute' waste ( $\because$ cigarette butts; $\square$ : cans; $\Delta$ : papers; $\mathrm{x}$ : plastic materials; $\circ$ : other waste).

Fig.2 The Numbers (a) and weights (b) of 'poi-sute' waste. 


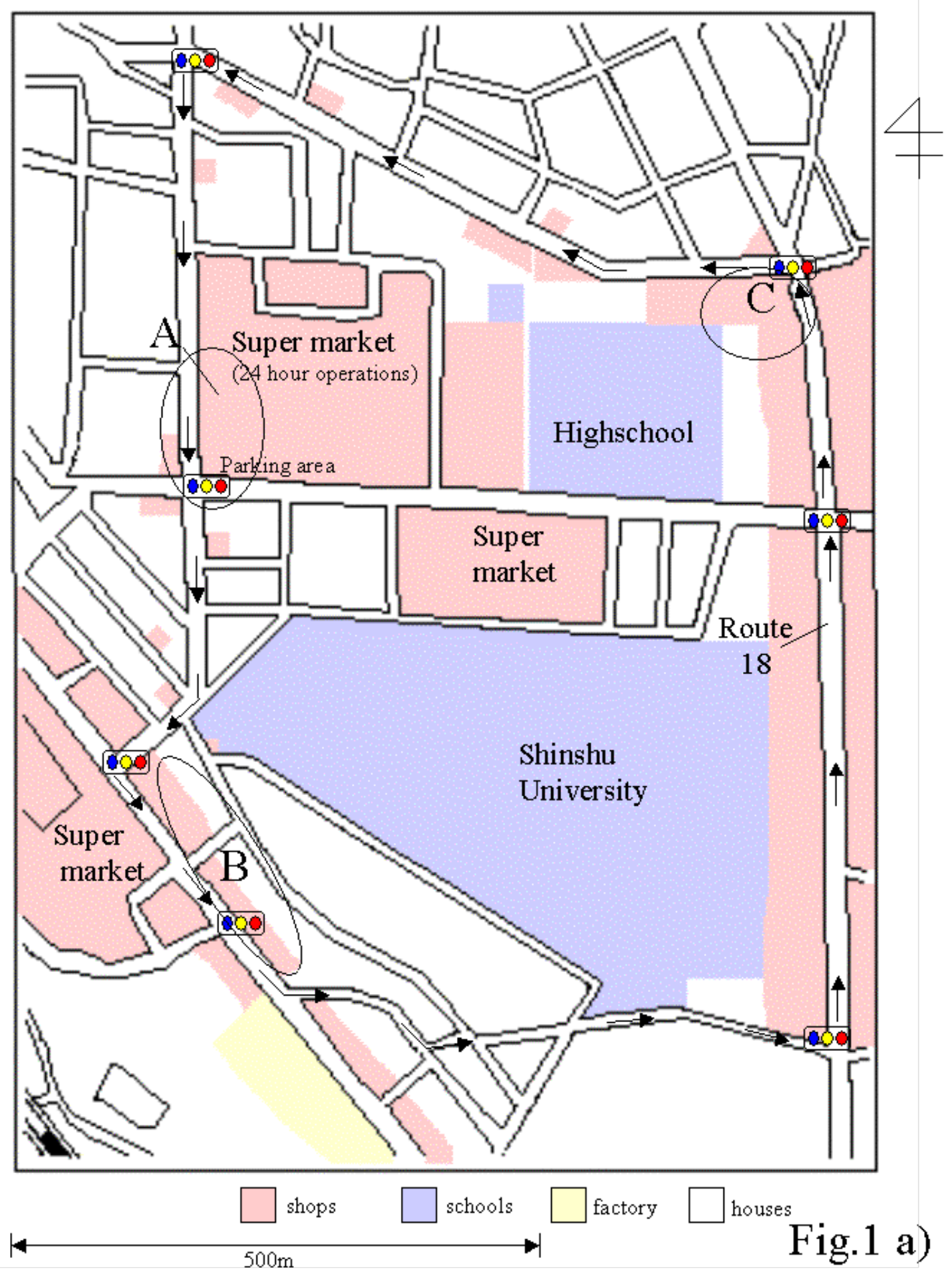


16th June 2007

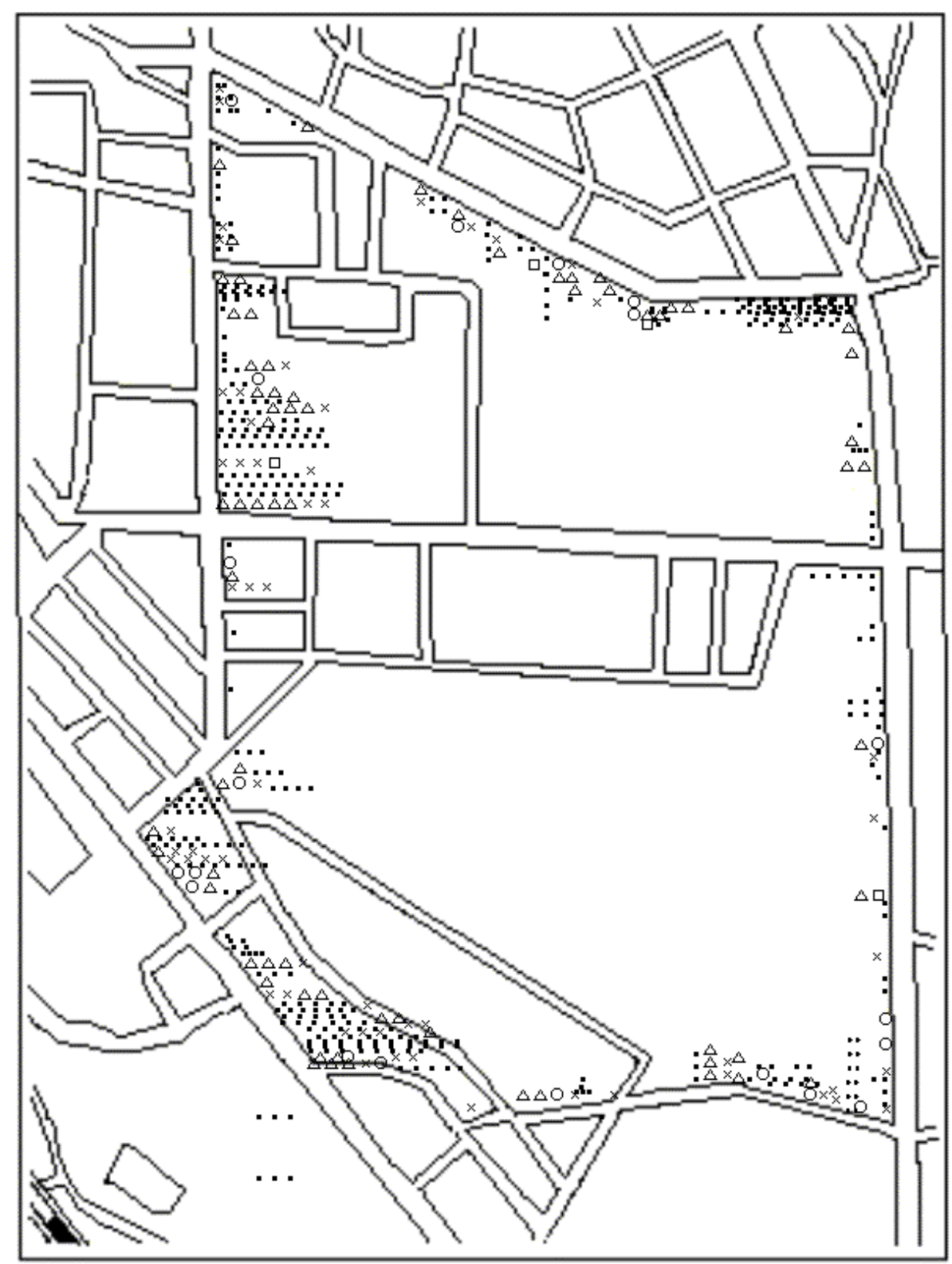

Fig. 1 b) 
a)

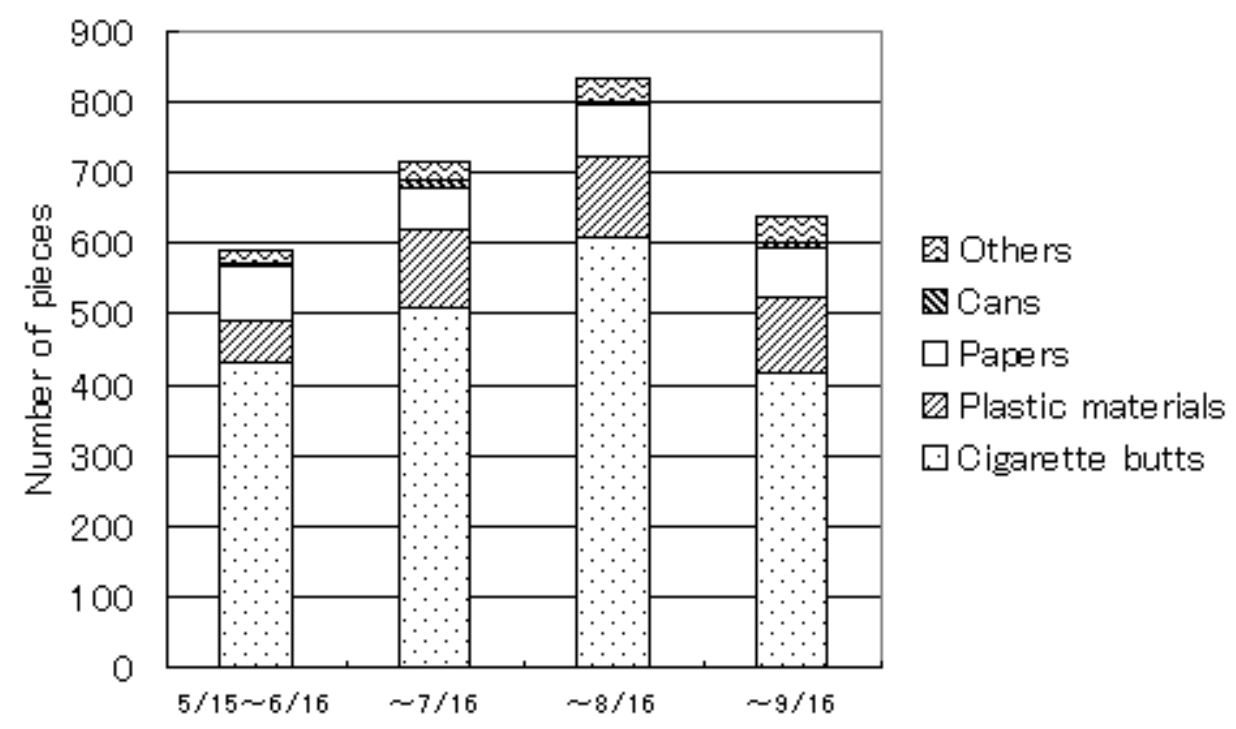

b)

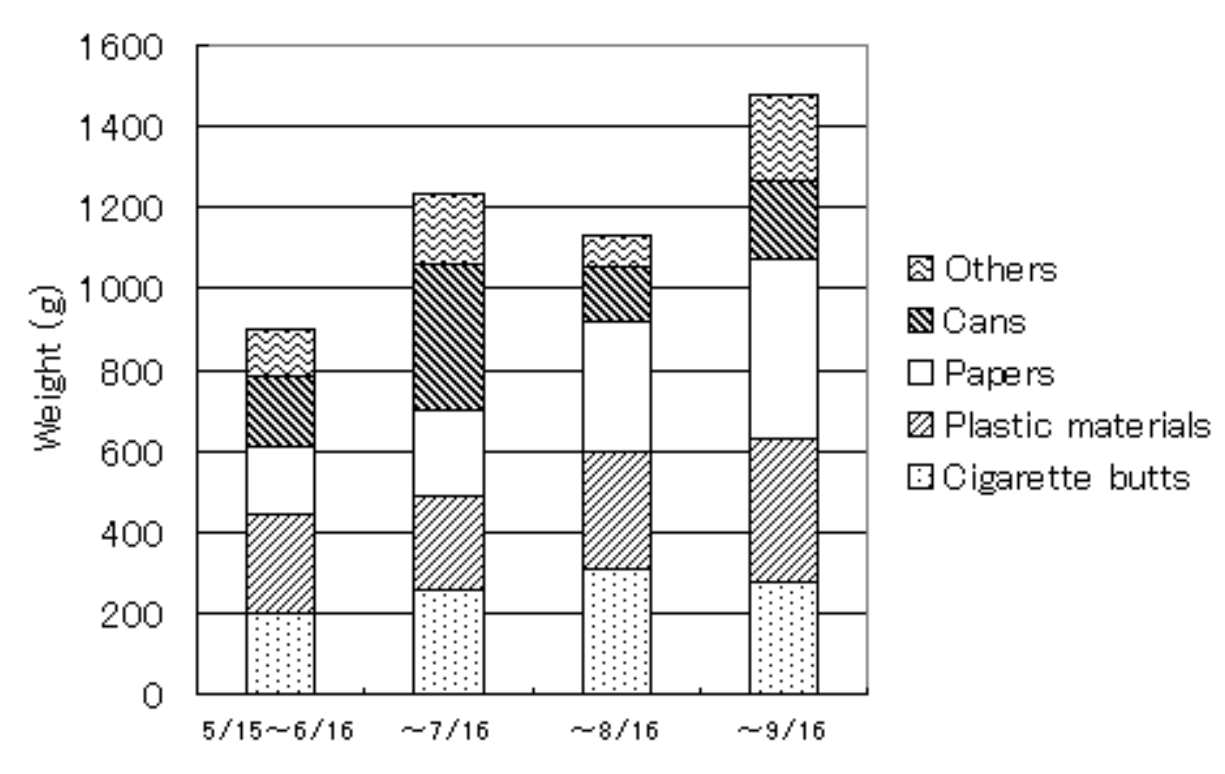

Fig.2 
Table 1 Characterization of 'poi-sute' waste

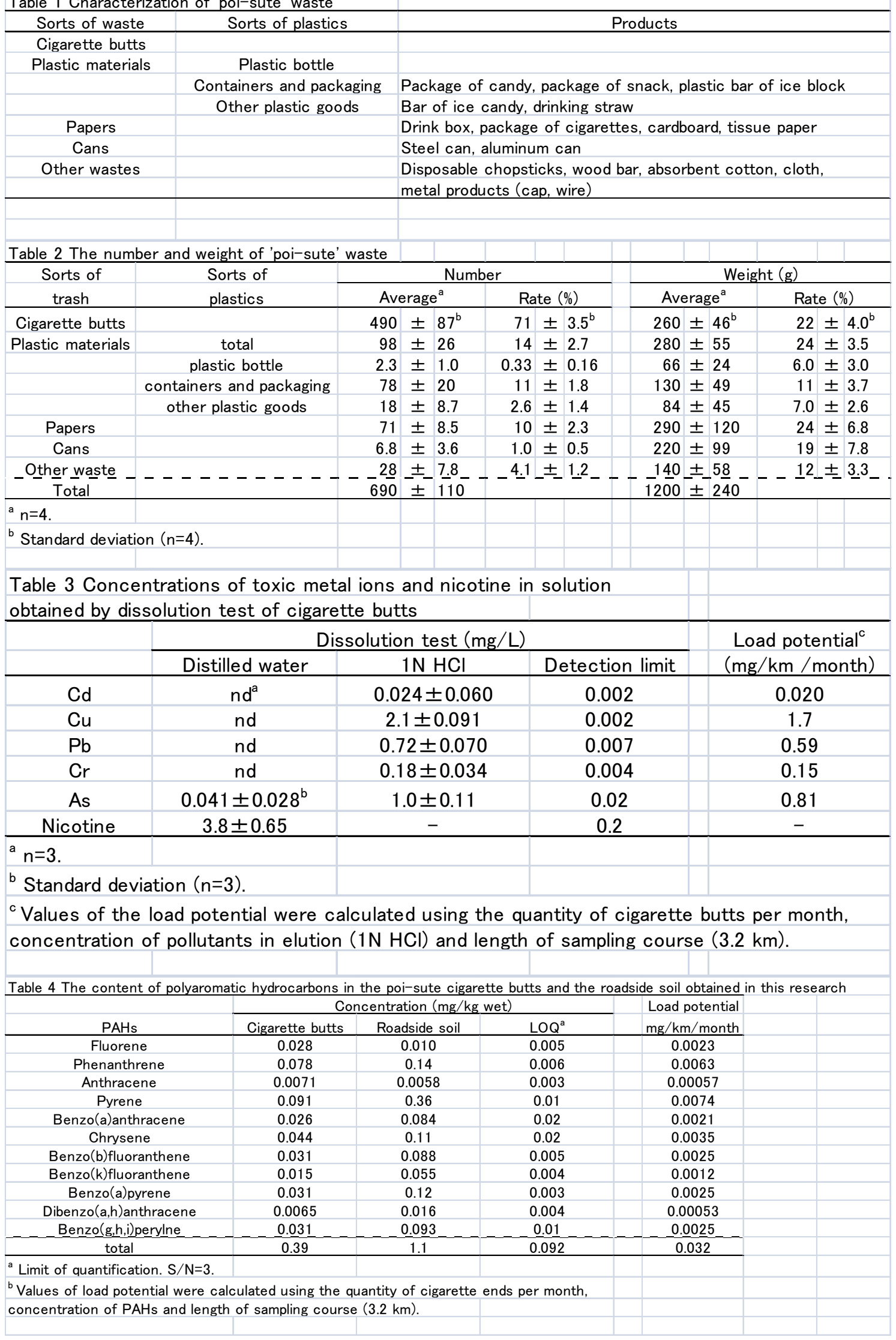


Table 5 Compositions of polyaromatic hydrocarbons (\%) in 'poi-sute' cigarette butts and roadside soil obtained in this research

\begin{tabular}{|c|c|c|c|c|c|c|}
\hline 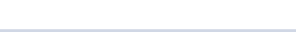 & \multicolumn{3}{|c|}{ Composition of $\mathrm{PAHs}(\%)$} & & & \\
\hline $\mathrm{PAHs}$ & Cigarette butts & Roadside soil & Gasoline engines $^{\mathrm{a}}$ & & & \\
\hline Fluorene & 7.2 & 0.92 & 6.4 & & & \\
\hline Phenanthrene & 20 & 13 & 4.2 & & & \\
\hline Anthracene & 1.8 & 0.54 & 1.6 & & & \\
\hline Pyrene & 23 & 33 & 10 & & & \\
\hline Benzo(a)anthracene & 6.7 & 7.8 & 6.4 & & & \\
\hline Chrysene & 11 & 10 & 6.1 & & & \\
\hline Benzo(b)fluoranthene & 7.9 & 8.1 & $14^{b}$ & & & \\
\hline Benzo(k)fluoranthene & 3.9 & 5.1 & 14 & & & \\
\hline Benzo(a)pyrene & 8.1 & 11 & 13 & & & \\
\hline Dibenzo(a,h)anthracene & 1.7 & 1.5 & no data & & & \\
\hline Benzo(g,h,i)perylne & 8.0 & 8.6 & 37 & & & \\
\hline \multicolumn{7}{|c|}{ a Percentages of PAH are calculated by the compositions of PAHs of vehicle soot (gasoline engine) in reference 14 . } \\
\hline The percentage is total o & nzo(b)fluoranthe & benzo(j)fluoran & lene and benzo(k)fl & uoranthene. & & \\
\hline
\end{tabular}

